\title{
Reflecting on what philosophy of epidemiology is and does, as the field comes into its own: Introduction to the Special Issue on Philosophy of Epidemiology
}

\author{
Jonathan Michael Kaplan ${ }^{1} \cdot$ Sean A. Valles ${ }^{2}$ iD
}

Received: 7 May 2019 / Accepted: 10 May 2019 / Published online: 17 May 2019

(c) Springer Nature B.V. 2019

\begin{abstract}
This article is an introduction to the Synthese Special Issue, Philosophy of Epidemiology. The overall goals of the issue are to revisit the state of philosophy of epidemiology and to provide a forum for new voices, approaches, and perspectives in the philosophy of epidemiology literature. The introduction begins by drawing on Geoffrey Rose's work on how to conceptualize and design interventions for populations, rather than individuals. It then goes on to highlight some themes that emerged in the articles that make up the issue: (1) philosophy of epidemiology and epidemiological theory-what they are and what they ought to be, (2) pluralism in measurement and causal attribution, (3) epistemic and non-epistemic values in disputes epidemiological practices, (4) decentering philosophy of epidemiology's Eurocentrism, (5) letting pragmatism guide uses of big data in epidemiology, and (6) revisiting the lessons of classic texts in epidemiological causal inference. The introduction concludes with comments on a philosophy of epidemiology debate we see on, regarding the politics of philosophy of epidemiology.
\end{abstract}

Keywords Causes of incidence $\cdot$ Philosophy of epidemiology $\cdot$ Politics $\cdot$ Population health

Sean A. Valles

valles@msu.edu

Jonathan Michael Kaplan

kaplanj@oregonstate.edu

1 School of History, Philosophy, and Religion, Oregon State University, Corvallis, OR 97331, USA

2 Lyman Briggs College and Department of Philosophy, Michigan State University, Holmes Hall Room 35E, 919 E. Shaw Lane, East Lansing, MI 48825, USA 


\section{Introduction}

Philosophy of epidemiology has developed rapidly in recent years, increasing in both depth and breadth. This special issue reflects both of these trends. Existing lines of investigation are developing at a rapid pace; new lines of argument are being formed to connect philosophy of epidemiology to other branches of inquiry. In a sense, this special issue is a bellwether for which older philosophy of epidemiology questions are likely to continue being debated (What are the proper roles of mechanistic evidence versus statistical evidence of population-level effects?) and which questions are strong candidates for additional engagement that would solidify them as key questions in the philosophy of epidemiology literature (How do the concepts and practices of racial health disparities epidemiology mesh with indigenous epistemologies and needs?).

As editors, we interpret the issue's content, and the field of philosophy of epidemiology more generally, in light of the perennial philosophical disputes within the field of epidemiology: the relationships between science-politics-advocacy, evidence and (un)certainty, the value of pluralism, tensions between academic ideals versus pragmatic limitations, etc. And since the welfare of populations and communities are always at stake in epidemiology, the issues at hand are directly or indirectly political issues.

The very meaning of epidemiology has long been disputed (Frérot et al. 2018). According to the World Health Organization, epidemiology "is the study of the distribution and determinants of health-related states or events (including disease), and the application of this study to the control of diseases and other health problems" (Frérot et al. 2018, p. 7). Or, as one of the US CDC puts it: "in epidemiology, the 'patient' is the community" (Centers for Disease Control and Prevention 2012, pp. I-4). This somewhat colorful metaphor echoes, in some ways, epidemiologist Geoffrey Rose's classic paper "Sick Individuals and Sick Populations" (1985)_if a population can be the patient, then it must be, after all, the population that is sick. If this is so, then what sort of task is it to study the causes of health-related issues at the community level, and what kinds of "treatments" appropriately target community health? When a community is "sick," how does one determine what is ailing it, and what treatments can be prescribed? As the papers in this special volume make clear, these kinds of questions are critical for both epidemiology and the philosophy of epidemiology. And as these papers also make clear, what kinds of questions the philosophy of epidemiology will ask, and what kinds of answer will be regarded as appropriate, are still very much contested.

Perhaps the best way to understand what this issues has attempted to accomplish, and we believe indeed has accomplished, is to revisit the question what is philosophy of epidemiology, now that many authors have had time to engage with and respond to Alex Broadbent's groundbreaking 2013 monograph, Philosophy of Epidemiology, offering the first complete book laying out a vision of what philosophy of epidemiology is (Broadbent 2013). As noted below, Broadbent is a contributor to this special issue, and the issue also includes a paper by one of us (Valles) disputing some of the work in his book, taking it to be too disconnected from the ethical goal of uncovering and responding to the causes of inequitable between-population health disparities and social determinants of health. 
Both Valles' paper and a separate forthcoming paper by co-editor Kaplan draw on Rose to pursue the work of refocusing attention on inequitable health disparities. Kaplan's paper, "Self-Care as Self-Blame Redux: Stress as Personal and Political," in the Kennedy Institute of Ethics Journal, argues that psychosocial stress, as one of the drivers of the poor health outcomes associated with the negative social determinants of health, has been inappropriately cast as an individual problem, to be solved through individual approaches (primarily 'mindfulness'-based interventions) (Kaplan Forthcoming). This, he suggests, constitutes a betrayal of the key insights of the research into the social determinants of health, and reflects a long-standing tension in the epidemiological community about if and how epidemiological researchers should advocate for radical social change (or even point out when radical social change is the only plausible intervention for a population health problem).

In constructing this forum revisiting the state of philosophy of epidemiology, we have sought to provide a forum for new voices in and new approaches to the philosophy of epidemiology, including papers focused on sciences/epistemologies other than the Western science/epistemology that now dominates the anglophone scientific and philosophical literatures. We believe that epidemiology and philosophy are ill-served by insularity. Critiques of shutting out non-Western perspectives from philosophy have had a welcome boost of attention that coincides with the simultaneous development of the philosophy of epidemiology literature (Van Norden 2017). Like the rest of philosophy, philosophy of epidemiology has been slow in this process. This is why it is so vital that the special issue includes papers that demonstrate the importance of engaging with: indigenous US epistemologies and experiences (Meissner), the epistemic framework of Classical Chinese Medicine (Lee), and the interplay between Guinean family ethics and scientific practices designed to test a vaccine in a Guinean population in an ethically and epistemically appropriate manner (Varghese). The issue's content examining unfamiliar epistemologies also includes Tulodzieki's paper using British history to illuminate philosophy of epidemiology. While British perspectives are more than amply represented in work on epidemiology, Tulodzieki compellingly demonstrates the importance of understanding the epistemology of miasma theory adherents who were skeptical of John Snow's famous now-revered proto-epidemiological study of cholera's spread in London via contaminated drinking water. If contemporary epidemiology and philosophy of epidemiology are to continue making progress on sorting through tangled evidentiary questions inherent to epidemiology, they would be wise to pay closer attention to their own history, in addition to others' histories and insights.

As is probably clear by this point, we (Valles and Kaplan), see our work and our goals for philosophy of epidemiology as motivated to a great extent by the work of Rose. Famously, he distinguished between the "causes of cases" and the "causes of incidence" of disease/ill-health (1985). Looking at members of a population, clinical medicine (e.g. a physician seeing patients in a hospital) attempts to determine why this patient, rather than another patient, got ill (the causes of cases), and prescribes an individual treatment aimed at ameliorating that illness in that patient. But Rose suggested, when we ask questions like "why do a higher proportion of the people in this population suffer the effects of this kind of ill-health than do people in that population?' a different sort of answer was called for. The question then is what counts as a cause of population-level health outcomes, and how can hypothesized 
causal pathways be tested? And if the causes identified by this kind of approach are not the sort traditionally addressed in biomedicine, how should epidemiologists respond?

When Rose wrote, in The Strategy of Preventive Medicine that "there is no known biological reason why every population should not be as healthy as the best" (1992, p. 1), he meant this as a challenge-the causes of poor population health can, he thought, be discovered, and if appropriate actions are taken, can be addressed. But when we turn our attention to the health disparities that exist between populations today, we find ourselves facing stark choices about what kinds of causes we will consider it reasonable for epidemiology to posit and test. In the papers in this volume, the authors grapple with what it means to find causes in epidemiology, with what kinds of actions are appropriate health interventions at the level of populations, with what counts as a population for the purposes of epidemiological research, and other related issues.

\section{The papers in the special issue}

\subsection{Philosophy of epidemiology and epidemiological theory: What they are and what they ought to be}

Taylor and Valles both argue for new ways of understanding and contending with the conceptual space of philosophy of epidemiology. Valles frames his article around the dual goals of pluralism and social responsibility, while Taylor frames his article around the idea of critical thinking in the sense that "understanding ideas and practices better when we examine them in relation to alternatives." Both authors worry about the dangers of narrow understandings of that conceptual space, but do so in different ways. Taylor lays out a wide range of ideas and conceptual-theoretical-philosophical debates (the distinction between philosophy of epidemiology and epidemiological theory is hazy), which he originally developed as a graduate course in epidemiological thinking. He introduces a large number of questions that he states are outside the scope of that paper, and two of them help clarify what Valles argues in his own paper. As Taylor puts it: "How much is philosophy of science about what epidemiologists do in practice versus what they leave unclear or under-examined, which philosophers try to resolve or shed light on?... The latter effort implies that the views or practices of scientists can be improved. By what means then do philosophers envisage that their accounts can influence researchers?"

While Taylor is more worried about mapping the key conceptual issues and ideas in epidemiological thinking, Valles is more concerned about how philosophers of epidemiology work within that vast conceptual space. Valles is motivated by a worry that philosophers of epidemiology seem to pursue their research topics and arguments without explicit or de facto tethering to professional norms of social responsibility. Epidemiologists and other public health scholars have designed stringent sets of professional norms for themselves, asserting among other things that rectifying inequitable health disparities is a chief professional goal, then holding each other publicly accountable when practices diverge from those norms. Philosophers of epi- 
demiology lack these formal and informal norms, and Valles argues that this needs to change. Valles sees a resolvable tension between the value of pluralism in philosophy of epidemiology, and recognizing that philosophers of epidemiology can and do (regardless of intent) influence epidemiology (responding indirectly to Taylor's previously quoted questions). Philosophers of epidemiology who are not straightforward practitioners of epidemiology operate in a sort of liminal space between philosophy and epidemiology, and Valles argues that the philosophy of epidemiology community, as a whole, has as a social responsibility to contribute to epidemiology's goal of addressing social determinants of health and inequitable health disparities between populations. He specifically proposes that philosophers of epidemiology should accomplish this in part by engaging with two particular epidemiological concepts: Rose's concept of "causes of incidence" and (connected to the "sick populations" concept discussed in Taylor's paper) and Link and Phelan's "fundamental cause theory" of how certain social determinants of health operate.

\subsection{Pluralism in measurement and causal attribution}

Broadbent's work is discussed by Valles as a contrasting case of how health disparities can be incidentally sidelined in philosophy of epidemiology work. But the papers by Broadbent, McClimans, Taylor, and Valles all agree on one general point: they all argue for the value of pluralism in debates over approaches to causal inference.

Broadbent takes aim at the Potential Outcomes Approach (POA) in epidemiology, which proposes a remarkably strict set of rules for when it is proper to speak of a relationship as a causal one, in essentially demanding that causal claims must rely on randomized controlled trials (e.g. the sort used when testing new pharmaceuticals) or at least rely on observational studies that closely mimic such trials. Broadbent objects on both philosophical grounds and on practical grounds. Philosophically, he argues that the POA restrictions on what can be qualified as causal are more restrictive than is warranted by the POA's stated metaphysical and epistemic commitments. Pragmatically, that restrictiveness inappropriately limits legitimate causal inferences in real cases such the effects of racism on heath, where race is not a manipulable variable but has been productively investigated in epidemiological research of the related causal pathways (related arguments appear in Valles' paper).

Taking a hermeneutical approach, McClimans is also concerned about epistemic standards and scientific practices that miss the forest for the trees. That is, she worries that some scholars have lost sight of the primacy of the patient, both patients' welfare and patients' epistemic contributions to health assessment. McClimans argues that the widely used category of 'patient-reported outcome measures' (PROMs) have been taken in the philosophical literature to be philosophically tied to the capabilities approach to health and to conceptions of subjective well-being. McClimans points out that neither connection is integral to PROMs' history nor its epistemic goals and overall framework. First, understanding these measures as entirely subjective is a misunderstanding of what PROMs do and why: "patient input must be 'directed' by patients, not simply reported". In other words, these are not merely means of consulting with patients on their subjective opinions about their own health, but rather they 
are a strategy built around a belief that autonomous patients are the rightful leaders of the processes that attempt to measure their health. Second, the capabilities approach is in tension with the PROM philosophical framework since the capabilities approach asserts a universal set of human capabilities that are at the heart of human well-being, regardless of the fact that individual patients can and sometimes do have conceptions of well-being that differ from the top-down dicta of capabilities approach scholars: "quality of life/PROMs should not be taken as an example of the capability approach to quality of life. Despite the fact that standardized measures do roughly follow the logic of the capability approach, this logic does not allow for a sufficiently responsive instrument, and thus discriminates against the quality of life of those it does not understand."

\subsection{Epistemic and non-epistemic values in disputes epidemiological practices}

Varghese and Jukola both build important connections between philosophy of epidemiology and the growing science-and-values literature. Varghese offers a defense of the Ebola ça Suffit trial of a candidate Ebola vaccine in Guinea, arguing that the trial designers appropriately navigated the overlapping epistemic and non-epistemic considerations. Most importantly, the trial declined to have a placebo control group at all, surmising that the relevant social and ethical value judgments made that option inappropriate, including taking into account the intuitive problem of using placebo vaccines in the midst of an epidemic of a lethal infectious disease. Instead of a randomized control trial using a placebo, the reputed (if disputed) "gold standard" of evidence, the researchers instead used a method in which, "clusters of individuals at high risk for infection were randomly assigned to either immediate or delayed vaccination". This, combined with providing healthcare and quarantines for all people in a cluster, and — crucially_respecting the family unit (rather than the individual) as the socially appropriate unit to include when designing clusters, led to a trial that Varghese argues properly allowed non-epistemic values to override the epistemic value of preferring a randomized control trial.

Jukola expands on a different branch of the science-and-values literature, showing how nutrition science can salvage epistemic trustworthiness from the looming background problem of commercial financial interests directly and indirectly intervening in nutrition science research. Jukola takes a nuanced view of how commercial interests have impacted the science, neither discarding nutrition science as wholly corrupted nor wholly absolving it. Instead, the paper argues that there are two different scales/levels of epistemic problems at work simultaneously. At the level of individual studies, we can and should scrutinize whether scientific methods and other aspects of the research process have been unduly influenced by commercial interests. But there is a macro issue of agenda-setting (how is the overall agenda of nutrition science set?) that is not reducible to a series of those micro problems: "If commercial interests contribute to the formation of blind spots that make it more difficult to implement efficient health policies, the epistemic trustworthiness of nutrition science is violated." 


\subsection{Decentering philosophy of epidemiology's Eurocentrism}

Meissner and Lee demonstrate the value of what a radically more inclusive philosophy of epidemiology could offer, both to philosophy of epidemiology and to other branches of scholarship. Meissner demonstrates how epidemiological and philosophical work on the racial health disparities is ill suited for tracking the health of indigenous US populations. That literature is largely designed to account for Black-White health disparities. But the complexities of contemporary US indigenous identity patterns challenge these practices. Among those problems: antiquated and overtly bigoted assumptions directly and indirectly control who is eligible for tribal membership and associated access to tribal social services and hence inclusion in associated health outcomes measures, and indigenous identity-formation practices and epistemologies do not map onto the folk racial concepts used in surveys. Incidentally tying together the special issue's contributors, Meissner contrasts the lessons it draws with caveats regarding using race concepts in epidemiology that were offered in earlier work by co-editors Kaplan and Valles (writing separately).

Lee's paper for the issue accomplishes the related goal of putting contemporary philosophy/theory of epidemiology in conversation with Classical Chinese Medicine, as well as ecological theory. While Meissner's paper shows the inconsistencies between indigenous epistemologies and US epidemiological disparities research epistemologies, Lee's ambitious paper essentially shows that there are robust epistemological similarities between the epistemologies of contemporary epidemiological theory, ecosystem science, and Classical Chinese Medicine. Among these unifying features are a holistic (non-reductionistic) appreciation of the "biotic and abiotic components which make up a particular ecosystem, the relationships between these with the ecosystem as a Whole, not to mention with other ecosystems." Among other insights, Lee shows that epidemiology has more in common with Classical Chinese Medicine than it does with biomedicine, in part because both commit to models of health causation that are, "multi-factorial, non-linear and reciprocal, and with feedback loops."

\subsection{Letting pragmatism guide uses of big data in epidemiology}

Leonelli and Tempini's paper and Grüne-Yanoff's paper both show the importance of strengthening ties between philosophy of epidemiology and data science. Leonelli and Tempini show the complexities of 'data mash-ups', illustrating how philosophy of epidemiology, philosophy of scientific models, and philosophy of data science can be mutually informative. A key finding is that such data mashups, such as linking weather data (e.g. temperature and location) with epidemiological data (e.g. hospital admissions from heat stress) to generate a unified model are neither straightforwardly worthwhile nor straightforwardly worthless. Rather, such mashups require careful attention to contexts and purposes. For instance, location is often explicitly treated as an "invariant," but Leonelli and Tempini show that (geo)location is conceptualized and operationalized in such a wide variety of different ways that location is not so fixed/stable/invariant after all. This complicates the epistemic features of the mashup process and of the potential practical uses thereof. Is mashing up such data a good 
means of generating predictions of things such as epidemiological effects of environmental causes? It depends on the relationships between the goals of a specific predictive task and how effectively researchers scrutinize the origins and the context of the data at hand.

Grüne-Yanoff examines the strengths and limitations of different types of simulation models, offering new insights into the benefits and drawbacks of simulations that use different types and degrees of abstraction, in the specific case of when simulations are needed for policy-making purposes, as was the case when the US sought to develop contingency plans based on the potential effects of a smallpox bioterrorism attack. Grüne-Yanoff begins by creating three categories for the types of epidemiological models that are used to simulate epidemiological events. Macro Equation models are the oldest type, generating predictions based on epidemiological dynamics equations that represent interactions between the infected and the uninfected, with one key drawback being that the model uses idealizations that do not neatly map onto the ways that real smallpox infected and uninfected people interact. Massive Simulation Models seek to overcome the limitations of Macro Equation Models by modeling the behavior of individual agents by incorporating more and variables, stretching model complexity to the limits of existing computing technologies. Abstract Simulation Models take a similar strategy as Massive Simulation Models, but are intentionally restrained for pragmatic reasons, such as to make them more transparent to observers who wish to examine the components of the model. Grüne-Yanoff counterintuitively argues that Macro-Simulation models' complexity creates the illusion of being epistemically superior, while actually being more opaque and more prone to leading policymakers to make mistaken inferences from the model. Macro-equation models can be very useful for some policy purposes, despite the presence of idealizations. Meanwhile, Abstract Simulation Models can be pragmatically superior to the more complex Massive Simulation Models by virtue of being relatively easier to assess and use.

\subsection{Revisiting the lessons of classic texts in epidemiological causal inference}

Tulodzieki and Williamson offer complementary studies of causal inference in the epidemiology of diseases with disputed etiologies. Tulodzieki offers this in a historicalphilosophical reexamination of John Snow's famous 1853-4 study of a London cholera outbreak; Williamson offers this in an examination of the debate over Zika virus' teratogenic (birth defect) effects. Tulodziecki powerfully argues that contemporary scholars have (implicitly or explicitly) drawn the wrong conclusions from Snow's study-central to epidemiology's self-mythology_using the benefit of hindsight to wrongly turn Snow into an epistemic hero for his simple explanation of cholera (contagion via contaminated water) and presuming contemporary skeptics were epistemically inferior or epistemically vicious for explanations that explained Snow's data via appeals to miasma theory (toxicity via exposure to organic decay, mediated by predisposing factors). Reductive history begets bad historical lessons for contemporary disputants in epidemiological debates, and Tulodziecki shows that Snow's contemporaries were not foolish for being skeptical of his account. 
Williamson points out that a key obstacle in contemporary investigations of Zika's teratogenicity are rooted in the challenge of synthesizing disparate pieces of evidence: "A problem is posed by the use of multiple sets of criteria to establish a causal claim such as the teratogenicity of Zika. It is not clear how to evaluate and compare sets of criteria, nor how to decide whether, for a given set of criteria, the evidence suffices to establish causality. The epistemological framework developed in this paper is intended to address this problem." Williamson constructs a framework—and accompanying diagram - proposing a set of considerations that can together establish a causal relationship like that of Zika and birth defects: clinical/epidemiological evidence, mechanistic evidence, mechanistic hypotheses, and the relationships between these considerations. Tulodzieki and Williamson both engage with foundational scholars in epidemiological theories of causation-Snow for Tulodzieki and Austin Bradford Hill for Williamson - and in both cases the papers show the limitations of these earlier scholars' work and offer positive new insights into how to better understand causal inference.

\section{Challenges ahead for philosophy of epidemiology}

Returning to this paper's earlier points about sick individuals and sick populations, there have been multiple different calls for recognizing that the causes of incidence are often political in nature. Lewontin's argument that high rates of tuberculosis are caused by social/political conditions, and that the Mycobacterium tuberculosis bacterium is better thought of as the agent of tuberculosis, and not the cause, is one version of this (Lewontin 1991, pp. 42-42). Link and Phelan's "fundamental causes" approach (that Valles makes use of in his contribution) is another. Lewontin was making an explicitly political point when he wrote that "we might be justified in claiming that the cause of tuberculosis is unregulated industrial capitalism, and if we did away with that system of social organization, we would not need to worry about the tubercle bacillus" (1992 p. 42). The major proponents of research into the social determinants of health (e.g. Wilkinson, Marmot, etc.) tend to be somewhat more circumspect, but even so, these approaches explicitly acknowledge that if epidemiology ought to focus on what Rose called the causes of incidence, then epidemiology will need to be political; if the social determinants of health are fundamental to population-level health outcomes, then intervening in population-level health outcomes will require a social/political intervention.

There is nothing ethically or politically neutral about which questions, authors, topics, epistemologies, etc. ought to be included in philosophy of epidemiology. The question what is philosophy of epidemiology? looms over everything in this special issue. Even in the development of this special issue that question contributed to the length and difficulty of the process, despite support from the handling Editor-in-Chief Catarina Dutilh Novaes, the Synthese Editorial Assistants, and the journal generally. Who is a qualified peer reviewer of a philosophy of epidemiology paper that connects to an area of work unfamiliar to other philosophers of epidemiology? This was a recurring challenge with no easy answers. Which work qualifies as being philosophy of epidemiology at all? For instance, co-editor Kaplan's aforementioned paper on self- 
care was planned to appear in the issue but reviewers interpreted it as too far afield (a frustrating event that had the silver lining of anecdotally supporting our contention that the field is due for an expansion of its scope!).

As co-editors, we see debates over the politics of philosophy of epidemiology on the horizon, and have both sought to lay out what some of those debates will need to address. Valles shows that epidemiologists' debates over their sociopolitical/ethical obligations have been explicit and fruitful, while philosophers of epidemiology have not been so willing to engage in analogous debates. Kaplan (Forthcoming) makes a related point, showing what happens when an issue (stress) gets reclassified from a being populational/epidemiological phenomenon (we need to take care of our overstressed population!) toward being an individual/medical issue (our population has a lot of overstressed people who each need to take better care of themselves!). This is not to say that there are easy answers here. If, e.g. income inequality is one of the driving forces behind poor health outcomes (via some variety of pathways), does this imply that epidemiologists should be focused on tax policy as a mechanism for improving population-level health outcomes? Should their attention be on specific environmental hazards, or is doing so ignoring the "fundamental" causes of disease, and fetishizing particular risks in ways that will not in the end improve population-level health outcomes?

Again, these are the sorts of political debates that we see on the horizon for philosophy of epidemiology. At this point in the field's development, we are heartened by this growth of breadth and depth. It is a field that is expanding beyond the agenda of any one or handful of people, and that is a very welcome thing.

Acknowledgements Thanks to Catarina Dutilh Novaes for the diligent work facilitating the issue as the handling Editor-in-Chief for the issue. Thanks, also, to the other Synthese Editors-in-Chief and staff members who helped along the way. Sahotra Sarkar shares credit for the proposal to commission the special issue. And, of course, we thank all of the contributors to the issue for their work and for their patience.

\section{References}

Broadbent, A. (2013). Philosophy of epidemiology. New York: Palgrave Macmillan.

Centers for Disease Control and Prevention. (2012). Principles of epidemiology in public health practice: An introduction to applied epidemiology and biostatistics (3rd ed.).

Frérot, M., Lefebvre, A., Aho, S., Callier, P., Astruc, K., \& Aho Glélé, L. S. (2018). What is epidemiology? Changing definitions of epidemiology 1978-2017. PloS One, 13(12), e0208442.

Kaplan, J. M. (Forthcoming). Self-Care as Self-Blame Redux: Stress as Personal and Political. Kennedy Institute of Ethics Journal.

Lewontin, R. C. (1991). Biology as ideology: The doctrine of DNA. New York: HarperCollins.

Rose, G. (1985). Sick Individuals and Sick Populations. International Journal of Epidemiology, 14(1), $32-38$.

Rose, G. (1992). The strategy of preventive medicine. New York: Oxford University Press.

Van Norden, B. W. (2017). Taking back philosophy: A multicultural manifesto. New York: Columbia University Press.

Publisher's Note Springer Nature remains neutral with regard to jurisdictional claims in published maps and institutional affiliations. 